\section{Considering audience}

The CERL Spotlight column offers an opportunity to step outside of the current issue of $C E R L$ and consider how it might be received not just by the current readership of CERL but to contemplate what the broader intended audience of ACRL members or academic librarians might want to know. This venue is a chance for $C E R L$ to reach out to those who may not be regular readers and demonstrate that the journal has something for almost every library perspective.

To effectively communicate the information of the message, it is critical to know the audience.

I had lunch recently with some colleagues, one who teaches political science to undergraduate students and one who teaches research methods and visualization. We landed on the topic of the importance of presenting information in a way that reaches the intended audience-a point with which everyone can probably agree. A specific case came up in conversation: presenting quantitative results in a map to illustrate relationships that one can easily see geospatially.

One colleague indicated that in presenting this data to a foreign government official, it was critical to consider how the official would look at the map-literally. In this case, the map projection generally used in the United States would make the profile and size of the country appear differently than they were used to. This seems relatively minor, but if in presenting the research results the audience is stuck on how their country is not represented in the way in which they are accustomed, they might also question the validity of the method and findings.

One colleague indicated that it was important to get the results of the data to the decision makers and that it was neither the time nor the

Wendi Kaspar is $C \& R L$ editor and policy sciences librarian at the Texas A\&M University Policy Sciences and Economics Library, email:warant@library.tamu.edu place to school them on projections or which one was more widely accepted.

The conversation continued with the question about whether this case was truly academic research or was it more of a marketing document. There were arguments that the way the information is packaged should not get in the way of the delivery versus the issue that it was compromising the (arguably) more accurate presentation in favor of something that played to the audience's assumptions.

It was an interesting conversation and one that I have been reflecting on and considering from different angles. On one hand, it is not unlike individuals choosing information sources (like, I don't know, broadcast news) that reinforces their own perceptions. On the other hand, when considering different perspectives, is one more "right" than another?

Scholarly research is often criticized as existing in a vacuum, not having a lot of practical application and not being accessible to practitioners or useful in the "real world." There are times that this does seem the case. Although scholarship is also perceived as being impartial and largely without bias, as though there is an objective "truth."

Ha.

So I go back to what I tell my students when they think about information-yes, consider the audience that you are writing for, but also consider audience in the sources you consult. People publish for a reason. If they didn't have a message that they wanted to send, they wouldn't bother.

When I ask students why people publish, almost invariably, the first response is "to inform." Okay, I admit I am jaded (especially after this latest election season), so my response to them is usually "Of what?" or "Why?" challenging them to follow through with the thought. While the authority of the source gets a lot of attention in information literacy and critical inquiry, in terms of assessing the quality, I would argue that the intended audience is at least as important, particularly because one can 
infer the motivation behind what is being published if the intended audience is known.

So why does CERL publish? Why do we exist? Who is our audience? All big questions, and I am only going to tackle the last one here. This is a question that we have been pondering as we consider the makeup of our editorial boards and work to make sure that they are representative of our audience. Which goes back to, Who is our audience?

I also consider a colleague in the Agricultural Communication and Journalism department (yes, there is such a discipline), who teaches survey research methods and radio broadcasting to agricultural students. You'd think that with the reduced number of family farms and the increase in farming as a business venture, there would not necessarily be a lot of call for this kind of applied discipline.

Well, my colleague has a very strategic take on this issue. He has said, repeatedly and vehemently, "We are not talking to the $3 \%$ or less that constitutes those who make up the agriculture industry, we are talking to the $97 \%$ of those who are consumers, supporters, stakeholders, advocates, and users of what the agricultural industry does, produces, etc." This seems disingenuous and largely political, but it is actually a profound shift in perspective. It is also one that is largely nontraditional and may seem somewhat threatening-that instead of those in a discipline talking among themselves, it is crucial for them to engage in a dialogue with the other $97 \%$.

So what could this mean for CERL? Is it really just for academic librarians? Can it be more broadly oriented than that? Can it engage in scholarly and professional discourse with those outside the profession, engaging more directly and effectively with higher education at large and with the disciplinary communities within it?

The variety of articles in this month's issue of CERL have broad appeal. The topics range from "Academic Uses of Video Games" to "User Experience of E-Books" and look at diverse constituencies, from library online orientation for English language learners to citation analysis of sources used by Latin American Studies faculty.

- Manuel Ostos. "What Do They Use? Where Do They Get It? An Interdisciplinary Citation Analysis of Latin American Studies Faculty Monographs, 2004-2013." Abstract: This citation analysis examines the ability of the local collection at Pennsylvania State University to meet the needs of global and area studies researchers focusing on monographs published by faculty members on Latin American studies in a ten-year period. The study focuses on book use to address the tempting notion that packages and online sources can fully and universally support international and area studies across multiple disciplines. The author assessed the works cited by such criteria as availability at the university libraries, language, place of publication, age of citation, and online availability. This study could inform collection development decisions and contributes to a general understanding of faculty research trends and the library's role in supporting the research related to Latin America across disciplines and academic units.

- Tao Zhang, Xi Niu, and Marlen Promann. "Assessing the User Experience of E-Books in Academic Libraries." Abstract: We report findings from an assessment of e-book user experience (search and information seeking) from usage data and user tests. The usage data showed that most reading sessions were brief and focused on certain pages, suggesting that users mainly use e-books to find specific information. The user tests found that participants tended to use default keyword searches and browse the search results. Experience levels with e-books and features of e-book platforms influenced users' information seeking in ebooks. The assessment results have significant implications for designing e-book features to support users' reading strategies and help libraries create a consistent user experience.

- Jenny S. Bossaller and Heather Moulaison-Sandy. "Documenting the Conversation: A Systematic Review of Library Discovery Layers." Abstract: This article describes the results of a systematic review of peer-reviewed, published 
research articles about discovery layers, userfriendly interfaces or systems that provide single-search box access to library content. Focusing on articles in LISTA published from 2009 to 2013, a set of 80 articles was coded for community of users, journal type, research method, and results. The findings suggest sustained, and potentially a converging, professional interest in discovery layers over time. They also demonstrate what has not been studied, finding very little research about how discovery layers affect public libraries or children.

- Ellen Nierenberg. "A Comparison of Nursing and Teacher Education Students' Information Literacy Learning: Results from Norway, 2016." Abstract: This study measures first-year undergraduate students' self-assessments and learning outcomes in information literacy skills in their first months of higher education in Norway. Comparisons are made between nursing students and teacher education students. Surveys were conducted before the library's information literacy course and after both library instruction and the submission of an academic paper in which citations were required. Survey questions were specifically related to evaluating sources, avoiding plagiarism, and citing sources. Results show significant improvement, especially in students' ability to cite sources. There were small differences between student groups.

- Frans Albarillo. "Is the Library's Online Orientation Program Effective with English Language Learners?" Abstract: In this paper, the author examines four years of assessment data (N=4,786) from Brooklyn College's Library Online Orientation Program (LOOP; url: https://library.brooklyn.cuny.edu/resources/ loop/loop.php), which is used to provide all English 1010 students with an orientation to the library, to see if English language learners (ELLs) are performing as well as their non-ELL peers. This paper also reports on how useful the LOOP is to ELLs when compared to nonELLs. By comparing data from ELL and non-ELL students using several independent sample T-tests, this paper shows that ELLs on the average scored lower on the quiz component of the LOOP than non-ELLs, though they found the LOOP tutorial more useful. In addition to reporting these assessment results, this paper includes a review of the different kinds of ELLs, discusses how to statistically operationalize this population for further quantitative studies for other libraries who would like to include these additional independent variables in their assessment data collection, and provides suggestions for making the LOOP more useful to ELL students in the future.

- Shannon L. Farrell, Amy E. Neeser, and Carolyn Bishoff. "Academic Uses of Video Games: A Qualitative Assessment of Research and Teaching Needs at a Large Research University." Abstract: Academic libraries develop collections and services for scholars who use video games in teaching and research. However, there are no assessments of related information and technology needs. The authors conducted 30 semistructured interviews to gather data about these needs and understand how the University of Minnesota Libraries can facilitate access to games and technology. A total of 28 interviewees used games in research, and 23 used games in teaching. We identified a variety of information and technology needs, and many showed strong disciplinary trends. The findings can inform needs-based multidisciplinary strategies to develop video game services and collections relevant to unique academic communities.

- Scott Spicer and Andrew Horbal, "The Future of Video Playback Capability in College and University Classrooms." Abstract: Instructional support is one of the primary reasons academic libraries collect video materials. Nonetheless, no one has published research into the perceptions of the people who install and maintain the equipment used to play these materials in college and university classrooms regarding the longevity of physical media formats. To address this gap in the literature, the authors of this paper surveyed classroom audiovisual support professionals from 49 ARL institutions and conducted seven followup interviews. The results indicate steps that academic libraries need to take now, if they want their video collections to remain relevant and accessible. $\boldsymbol{n}$ 